\title{
MICROPUNCTURE STUDY OF DISTAL TUBULAR FUNCTION OF CAT KIDNEY
}

\author{
Akiyoshi SUZUKI \\ Department of Pharmacology, Faculty of Medicine, University of Tokyo, \\ Bunkyo-ku, Tokyo
}

Recerved for publication August 26, 1970

Micropuncture studies of the tubules accesible on the surface of the mammalian kidney have been performed usually in the rat, dog and monkey.

The tubular fluid from early distal tubule in the rat was always hypotonic to plasma (1), but it reached isotonic to plasma in the late portion of the distal tubule (2-5). In contrast to the observation in the rat, it has been demonstrated that the tubular fluid was markedly hypotonic to plasma along the entire length of the distal tubule in the dog during antidiuretic as well as diuretic state $(6,7)$. In the kidney of the rhesus monkey, the distal tubular fluid was also bypotonic to plasma during hydropenia (8). The fact mentioned above has suggested that the distal tubular function of the rat kidney was different from that of the dog and monkey kidney. The micropuncture study of the cat kidney has not been reported.

The present study was designed to investigate the pattern of the tubular function of the cat kidney.

\section{METHODS}

Renal micropuncture experiments were performed on twenty-five male and female cats weighing from 2 to $4 \mathrm{~kg}$. Six cats were kept away from water 24 hours before experiments. The remaining cats were allowed free access to water before experiments, three of them were loaded water $(10 \mathrm{ml} / \mathrm{kg})$ via a gastric tube just prior to experiments, and one cat was injected $20 \mathrm{ml}$ of $0.9 \%$ saline intravenously immediately before micropuncture.

Initially anesthesia was induced by ether. The trachea was exposed in order to insert an cndotracheal tube and respiration was maintained by an artificial respirator. Polyethylene catheters were inserted into both hindlimb veins for injection and blood collection. A polyethylene catheter was inserted into the ureter of the experimental side in some cases for collection of urine samples.

Cats were immobilized by intravenous administration of Flaxedil $(3 \mathrm{mg} / \mathrm{kg})$ and this was added $1-1.5 \mathrm{mg} / \mathrm{kg}$ in case of need during experiment.

The left kidney was exposed, isolated from adipose tissues and decapsulated partially. The kidney was fixed in order to prevent respiratory movement with holders at the upper and lower sides of kidney. Care was taken not to disturb the renal blood flow. Warmed liquid paraffin oil was dropped on the surface of the kidney throughout the experiment. 
Micropipettes of Pyrex glass were prepared by a microelectrode puller and sharpened by a small grinder. Usually the tips of the pipettes were less than 10 microns in outer diameter. Micropipettes were filled with liquid parafîn oil, colored by oil blue and previously saturated with water. Micropuncture was performed under a binocular microscope at a magnificant of 80 -fold. The surface of the kidney was illuminated by a glass rod of Knisely type. One or two samples of proximal fluid and two to ten samples of distal tubular fluid were collected from the surface convolutions during experimental period.

The identification of distal tubules was facilitated by an intravenous injection of small amounts of $5 \%$ lyssamine green dissolved in $0.9 \%$ saline (9). Lyssamine green appeared in distal tubules about 50-80 seconds after injection. Blood was collected from hindlimb vein before, during and after experiment. In some cases, latex was injected into the tubules after the experiment and the kidney was removed and macerated wilh $\mathrm{HCl}$ and water, in order to isolate the punctured tubules and to identify the puncture sites. Their locations in their respective convolutions were measured with an eyepiece micrometer. On the case of the measurement the proximal tubule is defined to extend from the glomerulus to the thin segment of the loop of Henle and the distal convolution from the macula densa to the distal tubular junction to the collecting duct.

Measurement of osmolality and Na concentration:

After the collection of tubular fluid into the micropipette small amounts of liquid paraffin was sucked from the tip of the same micropipette, so the collected tubular fluid was put between liquid paraffin droplets in the micropipette. The tip of the micropipette was sealed. The osmolalities of tubular fluid, plasma and urine were measured by Ramsay's microcryoscopic technique (10).

After the measurement of osmolality, the tubular fluid in the micropipette was blowed out into the siliconized plate filled with liquid paraffin. Na concentration was measured by Erma ultramicroflame pholometer using 3-4 nanoliter in volume. The measurement was usually done in duplicate. Na concentration of plasma and urine was measured by Evans-flame photometer.

Determination of inulin concentration:

In some experiments $1 \%$ inulin in isotonic saline was administercd intravenously at the rate of $20 \mathrm{ml} / \mathrm{hr}$. Micropuncture was performed after inulin equilibration. The tubular fluid was applied for inulin determination following the measurement of osmolality and Na concentration. The inulin concentration of tubular fluid was determined by the ultramicrofluorometric method of Vurek and Pergam using sample about 10 nanoliter in volume $(11,12)$. Inulin concentration of plasma and urine was measured by the anthrone method (13).

\section{RESULTS}

$\mathrm{Na}$ and osmolatity of distal tubular fluid:

Samples from distal tubules were analyzed for osmolality and Na concentration (Table 1, Fig. 1). Values of osmolality ranged from 91 to $334 \mathrm{~m} \mathrm{Osmol} / \mathrm{kg}$ water. Values of 
TABle 1. Osmolality and $\mathrm{Na}$ of distal fluid.

\begin{tabular}{|c|c|c|c|c|c|}
\hline & Cat No. & $\begin{array}{c}\text { Osmolality } \\
\text { (1n Osm/kg water) }\end{array}$ & (TF/P)Osm.* & $\left(\begin{array}{l}\mathrm{Na} \\
(\mathrm{m} \mathrm{Eq} / \mathrm{L})\end{array}\right.$ & $(\mathrm{TF} / \mathrm{P}) \mathrm{Na}^{* *}$ \\
\hline 1) & & 312 & 0.98 & 45.0 & 0.31 \\
\hline 2) & & 312 & 0.95 & 32.0 & 0.24 \\
\hline \multirow{2}{*}{\multicolumn{2}{|c|}{ 3) }} & 285 & 0.95 & 88.0 & 0.62 \\
\hline & & 242 & 0.80 & 83.0 & 0.56 \\
\hline \multirow{3}{*}{\multicolumn{2}{|c|}{ 4) }} & 242 & 0.74 & 35.5 & 0.25 \\
\hline & & 188 & 0.57 & & \\
\hline & & 269 & 0.82 & 40.0 & 0.28 \\
\hline \multirow{3}{*}{\multicolumn{2}{|c|}{ 5) }} & 182 & 0.55 & 74.0 & 0.49 \\
\hline & & 317 & 0.95 & 15.0 & 0.10 \\
\hline & & 306 & 0.92 & 37.0 & 0.24 \\
\hline \multirow{5}{*}{\multicolumn{2}{|c|}{ 6) saline injected }} & 102 & 0.44 & 32.0 & 0.17 \\
\hline & & 91 & 0.40 & 33.0 & 0.20 \\
\hline & & 145 & 0.63 & 62.0 & 0.38 \\
\hline & & 145 & 0.63 & 81.0 & 0.50 \\
\hline & & 264 & 0.77 & 70.0 & 0.43 \\
\hline \multirow{4}{*}{\multicolumn{2}{|c|}{ 7) water loaded }} & 161 & 0.48 & 37.0 & 0.27 \\
\hline & & 188 & 0.57 & 60.0 & 0.43 \\
\hline & & 172 & 0.52 & 35.0 & 0.25 \\
\hline & & 269 & 0.96 & 90.0 & 0.62 \\
\hline \multirow{4}{*}{\multicolumn{2}{|c|}{ 8) }} & 291 & 0.89 & 66.5 & 0.48 \\
\hline & & 334 & 1.02 & 79.0 & 0.57 \\
\hline & & 291 & 0.89 & 66.5 & 0.48 \\
\hline & & 291 & 0.89 & 69.5 & 0.50 \\
\hline & hydropenic & 242 & 0.76 & 73.0 & 0.46 \\
\hline \multirow{2}{*}{\multicolumn{2}{|c|}{ 10) hydropenic }} & 285 & 0.90 & 63.5 & 0.43 \\
\hline & & 279 & 0.88 & 37.0 & 0.25 \\
\hline \multirow[t]{3}{*}{ 11) } & water loaded & 312 & 1.00 & 19.5 & 0.13 \\
\hline & & 312 & 1.00 & 42.0 & 0.28 \\
\hline & & 301 & 0.97 & 39.0 & 0.26 \\
\hline \multirow[t]{4}{*}{ 12) } & hydropenic & 312 & 0.89 & 110.5 & 0.77 \\
\hline & & 167 & 0.48 & 47.0 & 0.33 \\
\hline & & 318 & 0.91 & 100.0 & 0.70 \\
\hline & & 205 & 0.58 & 38.0 & 0.27 \\
\hline \multirow[t]{6}{*}{ 13) } & hydropenic & 150 & 0.51 & 56.0 & 0.42 \\
\hline & & 102 & 0.35 & 23.5 & 0.17 \\
\hline & & 242 & 0.82 & 80.0 & 0.59 \\
\hline & & 172 & 0.58 & 66.0 & 0.49 \\
\hline & & 188 & 0.64 & 58.5 & 0.43 \\
\hline & & 199 & 0.67 & 89.5 & 0.67 \\
\hline \multirow{2}{*}{\multicolumn{2}{|c|}{ 14) }} & 307 & 0.89 & 100.5 & 0.74 \\
\hline & & 323 & 0.94 & 67.0 & 0.47 \\
\hline \multirow{3}{*}{\multicolumn{2}{|c|}{ 15) }} & 226 & 0.68 & 76.5 & 0.59 \\
\hline & & 221 & 0.66 & 80.0 & 0.62 \\
\hline & & 264 & 0.79 & 69.5 & 0.54 \\
\hline 16) & & 307 & 0.95 & 104.5 & 0.72 \\
\hline 17) & hydropenic & 269 & 0.85 & 56.0 & 0.37 \\
\hline
\end{tabular}




\begin{tabular}{lllll} 
& 312 & 0.98 & 44.5 & 0.30 \\
258 & 0.81 & 57.5 & 0.38 \\
226 & 0.71 & 50.0 & 0.33 \\
231 & 0.73 & 48.0 & 0.32 \\
18) hydropenic & 209 & 0.65 & 30.0 & 0.20 \\
177 & 0.55 & 43.0 & 0.29 \\
177 & 0.55 & 58.0 & 0.39 \\
& 317 & 0.98 & 50.0 & 0.33 \\
& 209 & 0.65 & 75.0 & 0.50 \\
& 215 & 0.67 & 47.0 & 0.31 \\
& 253 & 0.81 & 25.0 & 0.19 \\
& 301 & 0.97 & 48.0 & 0.37 \\
& 296 & 0.95 & 40.0 & 0.31 \\
& 280 & 0.90 & 59.5 & 0.45 \\
& 285 & 0.91 & 50.0 & 0.38 \\
& 274 & 0.88 & 34.0 & 0.26 \\
& 242 & 0.78 & 43.0 & 0.33 \\
& 318 & 1.02 & 35.5 & 0.27 \\
$3 n 1$ & 0.97 & 48.3 & 0.37 \\
& 296 & 0.95 & 57.5 & 0.44 \\
\hline
\end{tabular}

* (TF/P) Osm, =tubular fluid to plasma ratio of osmolality

** (TF/P) Na-tubular fluid to plasma ratio of $\mathrm{Na}$ concentration

Osmolality and sodium concentration in distal tubule of cat

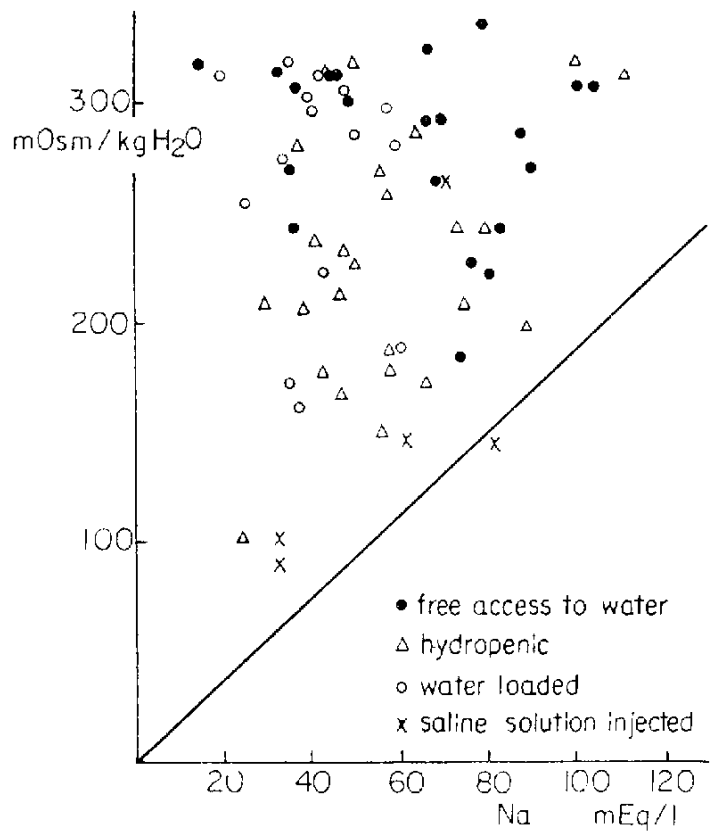

FiG. 1. Relationship between osmolality and $\mathrm{Na}$ concentration of same sample.

$\mathrm{Na}$ concentration ranged from 15.0 to $110.5 \mathrm{~m} \mathrm{Eq} / \mathrm{L}$. Tubular fluid to plasma ratios $(\mathrm{TF} / \mathrm{P})$ of $\mathrm{Na}$ concentration in distal tubules were within a range from 0.10 to 0.77 . While, those of osmolality ranged from 0.35 to 1.02 (Fig. 2). Na concentration of each distal 
Osmolality and sodium tubular fluid: Plasma ratio of cat kidney

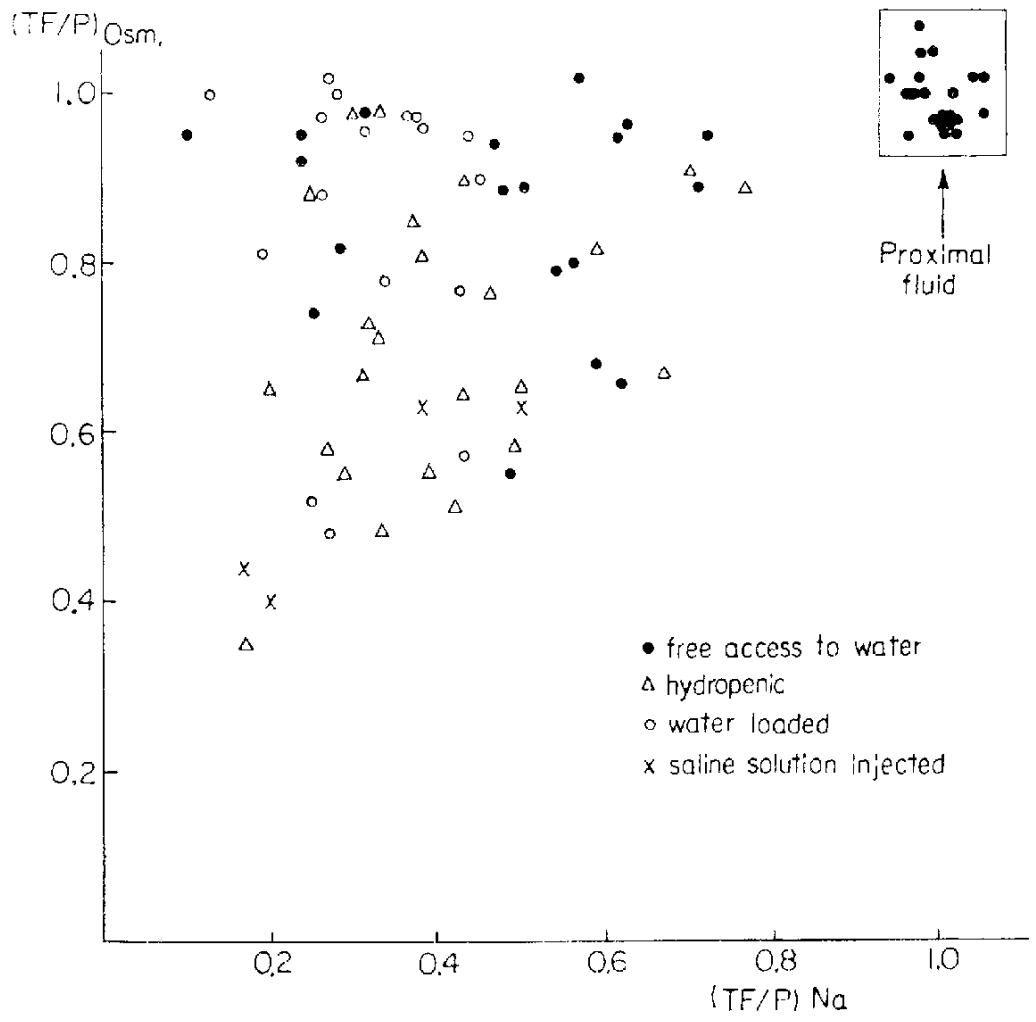

FrG. 2. Relationship between tubular fluid to plasma ratio of osmolality and that of $\mathrm{Na}$ concentration of same sample.

Osmolality and sodium tubular fluid: Plasma ratio in distal tubule of cat
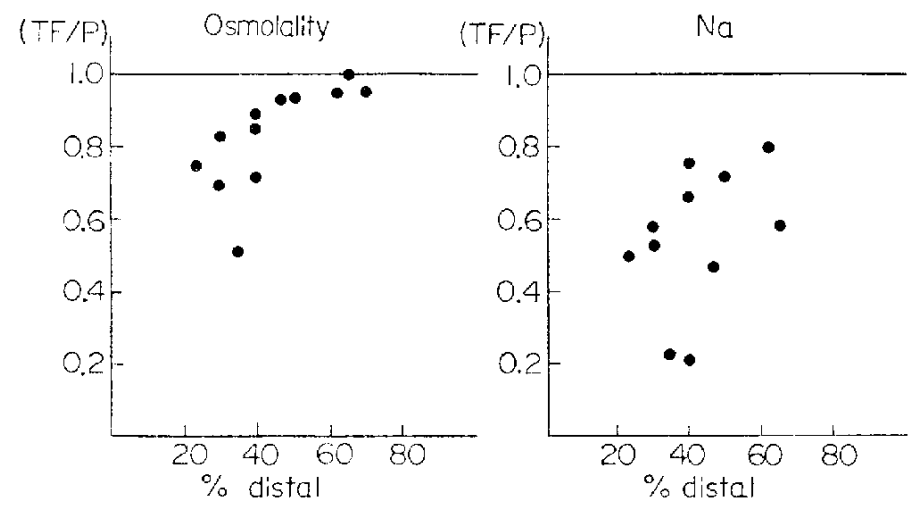

Fig. 3. Relationship between site of micropuncture and lubular fluid to plasma ratio of osmolality and that of $\mathrm{Na}$ concentration.

sample was much lower than that of proximal fluid and plasma in many cases. Other solutes besides $\mathrm{Na}$, e.g. urea and $\mathrm{K}$, seemed to contribute much to the osmolality of distal tubular fluid. There was no significant difference of osmolality and $\mathrm{Na}$ concentration in the distal tubule between the hydropenic and the water loaded cats. These results sug- 
gested that the tubular fluid might reach isotonic to plasma during the flow. In order to identify the micropuncture site, latex was injected into the tubular lumen and the microdissection of the tubular tissue was performed. In Fig. 3 the correlation between the osmolality as well as $\mathrm{Na}$ concentration and punctured sites of the distal tubule were shown.

The tubular fluid was hypotonic in the early distal tubule, and reached approximately isotonic in the late portion as shown in Fig. 3. On the other hand, $\mathrm{Na}$ concentration was lower than that of plasma along the entire distal length.

$\mathrm{Na}$ and osmolality of proximal tubular fluid:

One or two samples of proximal tubular fluid were collected in each cat. Na concentration of these samples we re from 126 to $162 \mathrm{mEq} / \mathrm{L}$. Proximal tubular fluid to plasma ratio (TF/P) of Na concentration was almost equal to unity. While, values of osmolality ranged from 285 to $361 \mathrm{~m} \mathrm{Osmol} / \mathrm{kg}$ water and all samples were almost isotonic with plasma along the entire proximal length (Table 2, Figs. 4 and 5).

TABLE 2. Osmolality and $\mathrm{Na}$ of proximal fluid.

\begin{tabular}{lcccc}
\hline Cat No. & $\begin{array}{c}\text { Osmolality } \\
\text { Osm/kg water })\end{array}$ & $(\mathrm{TF} / \mathrm{P}) \mathrm{Osm}{ }^{*}$ & $\begin{array}{c}\mathrm{Na} \\
(\mathrm{m} \mathrm{Eq} / \mathrm{L})\end{array}$ & $(\mathrm{TF} / \mathrm{P}) \mathrm{Na}^{* *}$ \\
\hline 1$)$ & 344 & 1.02 & 135.0 & 1.05 \\
& 323 & 0.95 & 135.0 & 1.05 \\
2) & 328 & 1.0 & 127.5 & 0.96 \\
& 312 & 0.95 & 127.5 & 0.96 \\
3) & 328 & 1.0 & 128.5 & 0.96 \\
4) & 318 & 1.05 & 138.5 & 0.98 \\
5) & 285 & 1.02 & 150.5 & 1.04 \\
6) saline injected & 318 & 1.0 & 152.0 & 0.99 \\
7) water loaded & 334 & 0.97 & 162.0 & 1.01 \\
8) hydropenic & 323 & 0.97 & 137.0 & 0.99 \\
9) & 317 & 1.0 & 143.0 & 0.98 \\
10) hydropenic & 318 & 1.02 & 143.0 & 0.94 \\
11) hydropenic & 339 & 0.97 & 145.0 & 1.01 \\
& 285 & 0.96 & 135.0 & 1.0 \\
12) & 296 & 1.0 & 130.5 & 0.97 \\
13) & 361 & 1.08 & 126.0 & 0.97 \\
14) hydropenic & 328 & 1.02 & 142.0 & 0.97 \\
15) hydropenic & 307 & 0.97 & 150.5 & 1.0 \\
16) water loaded & 312 & 0.97 & 151.5 & 1.01 \\
\hline
\end{tabular}

* $(\mathrm{TF} / \mathrm{P})$ Osm. = tubular fluid to plasma ratio of osmolality

** $(\mathrm{TF} / \mathrm{P}) \mathrm{Na}=$ tubular fluid to plasma ratio of $\mathrm{Na}$ concentration

\section{Water reabsorption:}

Net water reabsorption along the each segment of nephron was calculated from inulin concentrations in the tubular fluid. Plasma to tubular fluid ratio (P/TF) of inulin concentration represents the remained fraction of filtered water in the each portion of the nephron (Table 3, Fig. 6). About $50 \%$ of filtered water remained in the late surface convolu- 
Osmolality and sodium concentration in proximal tubule

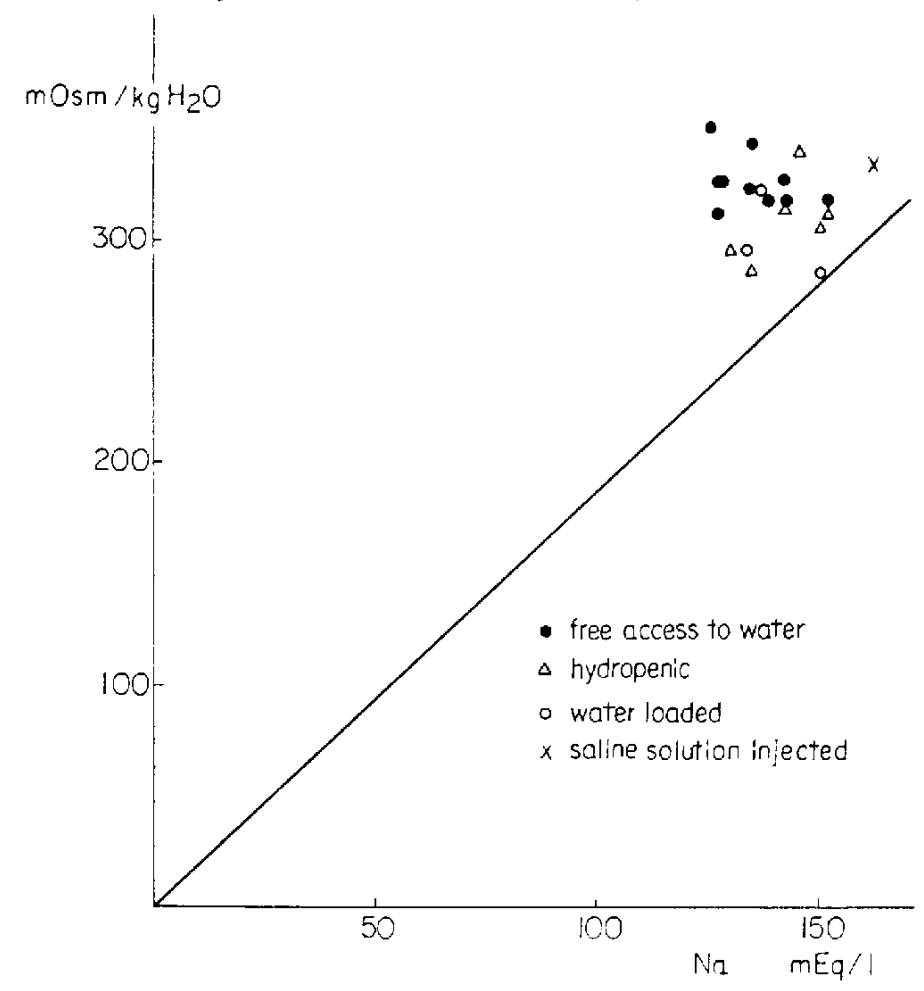

FIG. 4. Relationship between osmolality and $\mathrm{Na}$ concentration of same sample.

Osmolality and sodium tubular fluid: plasma ratio in proximal tubule
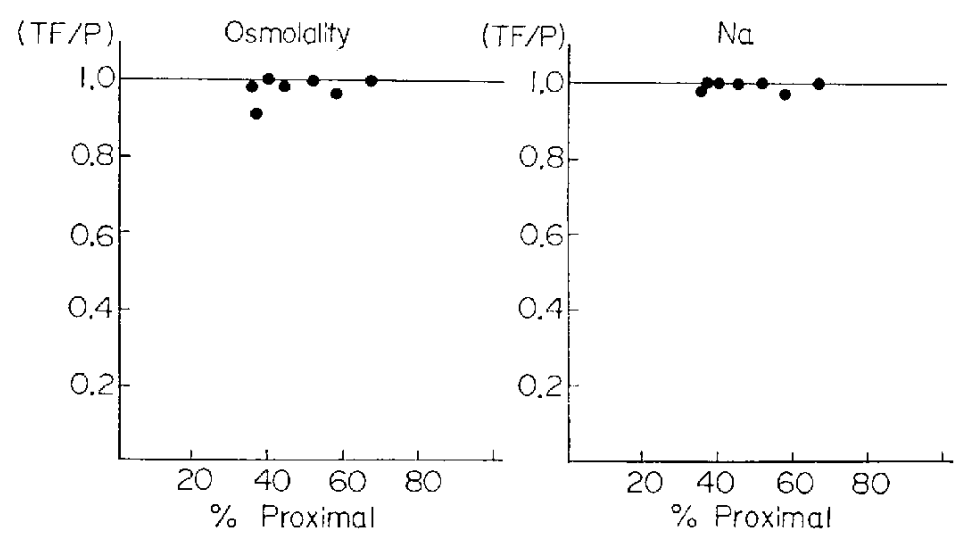

FIG. 5. Relationship between site of micropuncture and tubular finid to plasma ratio of osmolality and that of $\mathrm{Na}$ concentration.

tion of proximal tubule, the remained fraction of filtered water in the early distal tubule was about 15 to $17 \%$ of filtered water, and this water decreased further along the distal tubule.

This result showed that water was reabsorbed significantly along the distal tubule. 
TABLE 3.

\begin{tabular}{|c|c|c|c|c|c|c|c|}
\hline Cat No. & Location & $\begin{array}{c}\text { Osm. } \\
\text { (mOsm/kg } \\
\text { water) }\end{array}$ & (TF/P) Osm. & $\underset{(\mathrm{mEq} / \mathrm{L})}{\mathrm{Na}}$ & $(\mathrm{TF} / \mathrm{P}) \mathrm{Na}$ & $(\mathrm{P} / \mathrm{TF}) \mathrm{In}$. & $\begin{array}{l}(\mathrm{TF} / \mathrm{P}) \mathrm{Na} \\
(\mathrm{TF} / \mathrm{P}) \ln .\end{array}$ \\
\hline \multirow[t]{2}{*}{ 1) } & D* $47 \%$ & 280 & 0.93 & 72 & 0.47 & & \\
\hline & D $65 \%$ & 301 & 1.0 & 89 & 0.58 & & \\
\hline \multirow[t]{4}{*}{ 2) } & $\mathbf{P}^{* *} 37 \%$ & 318 & 0.91 & 130 & 1.02 & & \\
\hline & D $30 \%$ & 242 & 0.69 & 73.5 & 0.58 & 0.057 & 0.033 \\
\hline & D $70 \%$ & 334 & 0.95 & & & 0.033 & \\
\hline & $\mathrm{U}^{* * *}$ & 635 & 1.82 & 153.5 & 1.20 & 0.009 & 0.036 \\
\hline \multirow[t]{5}{*}{ 3) } & $\mathrm{P} \quad 52 \%$ & 339 & 1.0 & 150 & 1.04 & & \\
\hline & D $40 \%$ & 301 & 0.89 & 95 & 0.66 & 0.094 & 0.062 \\
\hline & D $62 \%$ & 323 & 0.95 & 116.5 & 0.80 & 0.063 & 0.05 \\
\hline & D $30 \%$ & 280 & 0.83 & 77 & 0.53 & & \\
\hline & $\mathrm{U}$ & 963 & 2.84 & 249 & 1.72 & 0.021 & 0.037 \\
\hline \multirow[t]{3}{*}{ 4) } & $\mathbf{P} \quad 58 \%$ & 318 & 0.97 & 150 & 0.98 & 0.400 & 0.392 \\
\hline & D $50 \%$ & 307 & 0.93 & 107.5 & 0.71 & & \\
\hline & U & 872 & 2.66 & 240 & 1.57 & 0.014 & 0.022 \\
\hline \multirow[t]{5}{*}{ 5) } & $\mathrm{P} \quad 36 \%$ & 312 & 0.98 & 138 & 0.99 & 0.390 & 0.387 \\
\hline & $\mathrm{P} \quad 45 \%$ & 312 & 0.98 & 141 & 1.01 & 0.456 & 0.459 \\
\hline & D $23 \%$ & 237 & 0.75 & 70 & 0.50 & 0.156 & 0.078 \\
\hline & D $40 \%$ & 269 & 0.85 & 106 & 0.76 & & \\
\hline & $\mathrm{U}$ & 667 & 2.10 & 165.5 & 1.19 & 0.052 & 0.062 \\
\hline \multirow[t]{6}{*}{ 6) } & P $\quad 67 \%$ & 339 & 1.03 & 143 & 1.02 & 0.450 & 0.459 \\
\hline & P $\quad 40 \%$ & 339 & 1.03 & 144 & 1.03 & & \\
\hline & D $35 \%$ & 167 & 0.51 & 32 & 0.23 & & \\
\hline & D $40 \%$ & 237 & 0.72 & 30 & 0.21 & 0.135 & 0.028 \\
\hline & D $31 \%$ & 156 & 0.48 & 27.5 & 0.20 & 0.170 & 0.034 \\
\hline & $\mathrm{U}$ & 1981 & 6.03 & 256 & 1.83 & 0.007 & 0.013 \\
\hline
\end{tabular}

* Distal tubulc

** Proximal tubule

:*** Ureteral urine

Location $=$ Site of fluid collected

Osm.- Osmolality

(TF/P) Osm. = Tubular fluid to plasma ratio of osmolality

(TF/P) $\mathrm{Na}=$ Tubular fluid to plasma ratio of $\mathrm{Na}$ concentration

$(\mathrm{P} / \mathrm{TF})$ In. = Plasma to tubular fiuid ratio of inulin

\section{Na reabsorption:}

The fraction of filtered sodium remained in the each portion of nephron is shown in Fig. 7. About $50 \%$ of filtered sodium was reabsorbed along the proximal tubule. The fraction of filtered sodium which entered the early portion of distal tubule was about $8 \%$. Large fraction of sodium was presumed to be reabsorbed in the Henle's loop and some fraction of sodium might be reabsorbed along the distal tubule.

\section{DISCUSSION}

In the mammalian kidney, it has been known that there are two different types as for the function of the distal tubule. In the dog as well as in the monkey the tubular fluid 
Ratio of inulin plasma: tubular fluid

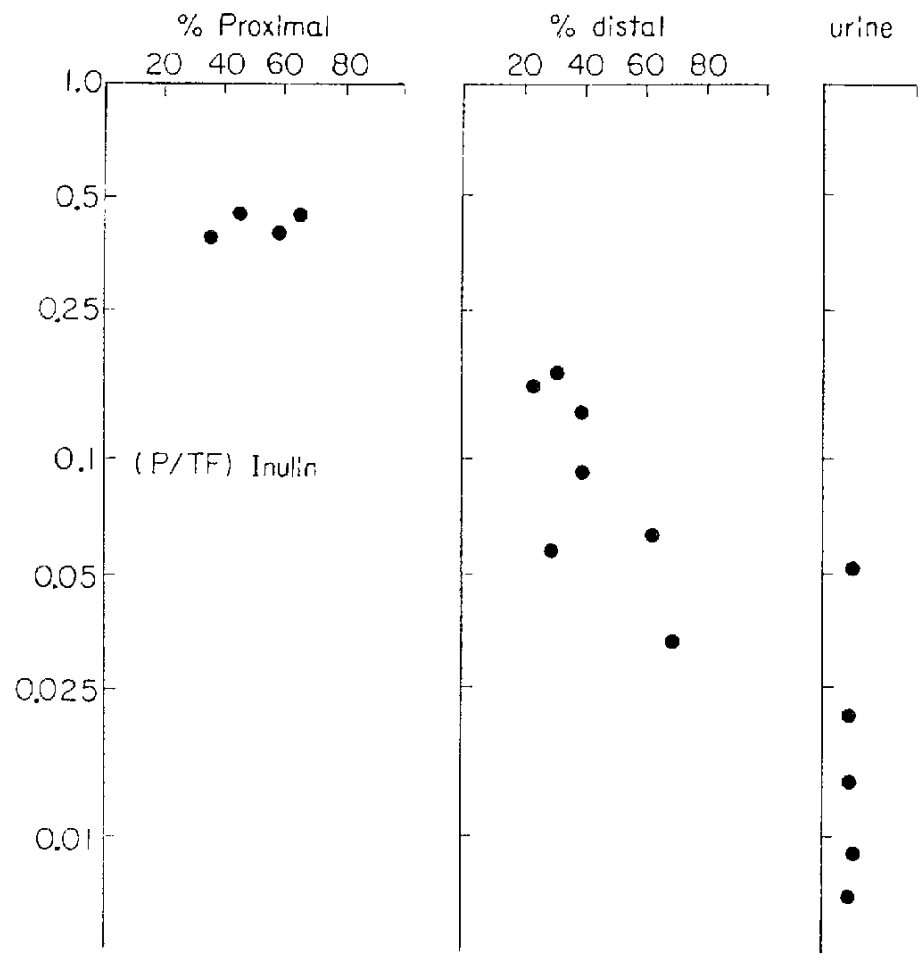

FiG. 6. Relationship between remained fraction of filtered water and site of fluid collection.

was always hypotonic along the entire distal convolution (6-8). While, in the rodents, c.g. the rat, distal tubular fluid was hypotonic only in the early portion but the osmolality elevated along the distal length to isotonic in the late portion (1-5). Micropuncture studies of the kidney have been performed generally in the rat, dog or monkey, and the function of the kidney of other animal, e.g. the cat, has not been studied. Therefore, the renal function of the cat, especially that of distal tubule, was investigated with micropuncture technique.

Both osmolality and $\mathrm{Na}$ concentration of proximal tubular fluid in the cat were roughly equal to respective value of plasma and the osmolality of distal tubular fluid was hypotonic in the early portion as well as in the rat, dog and monkey but reached isotonic in the late portion. In the dog, as well as monkey, fluid was always hypotonic along the entire distal tubule $(6,7,14)$. The cat was clearly different from the dog and monkey with regards to this pattern of the distal tubular fluid. In the dog, the permcability of the distal tubule to water was low. About one-fourth of the water was reabsorbed in the distal tubule (7). In the monkey, the pattern of the water reabsorption in the distal tubule was almost same as in the dog $(8,14)$.

On the other hand, the distal tubular fluid in the rat was considerably reduced to roughly onc-fourth of the water entered from loop of Henle. The fluid was passively 


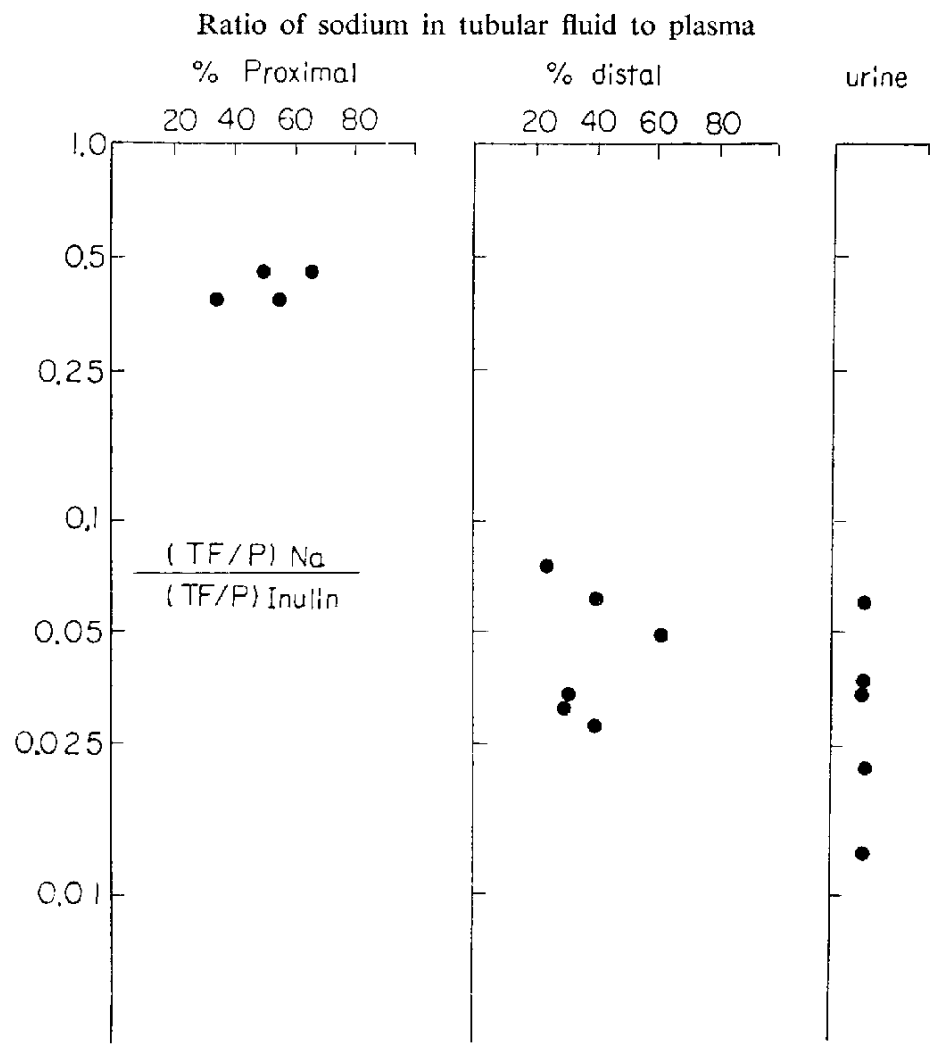

Fig. 7. Relationship between ramained fraction of filtered $\mathrm{Na}$ and site of fluid collection.

reabsorbed and the fluid in the distal tubule became isotonic (4). The findings reported here showed that the permeability of water in the distal tubule of the cat was similar to that of the rat.

The distal tubular fluids were collected in this experiment under various conditions and the osmolalities of these samples were iso- or hypotonic. The correlation between the osmolality and the site of puncture in the tubule was analyzed.

These facts suggest that the fluid becomes isotonic in the late distal tubule under the various conditions experimented in this study.

It could be concluded that the nature of the tubular nembrane of the water permeability in the cat was different from that of the dog or monkey, and was resembled to the rat.

\section{SUMMARY}

This experiment studied the distal tubular function of the cat kidney. Tubular fluid was collected by micropuncture technique from the surface convolutions of the proximal and distal tubules of the left kidney and the collected tubular fluid was analyzed for the osmolality and the concentration of sodium and inulin. 
Tubular fluid from the early distal tubule was hypotonic but was approximately isotonic to the plasma in the late portion. The sodium concentration of the distal tubular nuid was much lower throughout this segment than that of the plasma and the proximal tubular fluid.

The plasma to distal tubular fluid ratio of inulin decreased in the late distal tubule as compared with that in the early portion. This suggested that water was reabsorbed in the distal tubule of the cat kidney.

This study showed that the distal tubular function in the cat was different from that in the dog and monkey, but was resembled to the function of the distal tubule in the rat.

Acknowledgement: The author gratefully thanks Prof. F. Sakai and other members of kidney research group for their valuable comments and helpful assistance.

\section{REFERENCES}

1) WIRZ, H.: Physiol. Pharmac. acta 14, 353 (1956)

2) Gottschalk, C.W. and Mylle, M.: Am. J. Physiol. 196, 927 (1959)

3) Gottschalk, C.W.: Physiologist 4, 35 (1961)

4) Lassiter, W.E., Gottschalk, C.W. and Mylle, M.: Am. J. Physiol. 200, 1139 (1961)

5) Ulilrich, K.J., Schmidt-Niflsen, B., O'Dell, R., Pehlivg, G., Gotrscitalk, C.W., Lassiter, W.E., and Mylle, M.: Am. J. Physiol. 204, 527 (1963)

6) Clapp, J.R. and Robinson, R.R.: J. clin. Invest. 45, 1847 (1966)

7) Bexinett, C.M., Clapp, J.R. and Berluner, R.W.: Am. J. Physiol. 213, 1254 (1967)

8) Brevnler, B.M., Bennett, C.M. And Berliner, R.W.: Physiologist 10, 132 (1967)

9) Stelnilausen, M.: Arch. ges. Physiol. 277, 25 (1963)

10) Ramsay, J.A. AND BRown, R.H.J.: J. scicht. Instrum. 32, 372 (1955)

11) Vurek, G.G. and Pergam, S.E.: Analyt. Biochem. 16, 409 (1966)

12) Suzuki, A., IkEzawa, I. ANd SakaI, F.: Igaku No Ayumi 70, 127 (1969)

13) Fuhr, J., KaczmarczyK, J. and KrÜttgen, C.D.: Klin. Wschr. 33, 729 (1955)

14) Bennett, C.M., Brenner, B.M. ANd Berliner, R.W.: J. clin. Invest. 47, 203 (1968) 